\title{
ZAFRA Víctor, Manuel, La autonomía local en una Constitución reformada
}

\author{
Gustavo García-Villanova Zurita \\ Ayuntamiento de Granada (España) \\ ggarciav@granada.org
}

\section{NOTA BIOGRÁFICA}

Licenciado en Derecho y Graduado en Ciencias Políticas. Doctorando del programa de Ciencias Jurídicas de la Universidad de Granada. Secretario-Interventor en excedencia y funcionario del Cuerpo Superior de Administradores Generales de la Junta de Andalucía. Actualmente es Secretario de categoría superior y ejerce como Vicesecretario General del Ayuntamiento de Granada.

\section{RESUMEN}

Recensión del libro de Manuel ZAFRA VICTOR, La autonomía local en una Constitución reformada. Centro de Estudios Políticos y Constitucionales. Madrid, 2020.

La autonomía local se ha visto convertida en una materia sometida a reparto competencial entre Estado y Comunidades Autónomas, apartándose por este motivo de su concepción original. En la medida en que las Comunidades Autónomas la han intentado interiorizar, ha sido el legislador estatal quien ha salido en su defensa. La salida a esta situación se basa en la propuesta de una regulación de detalle en una posible reforma constitucional, que delimite un núcleo de funciones claras sobre materias concretas que permitan un desarrollo real de la autonomía política de los gobiernos locales.

\section{PALABRAS CLAVE}

Autonomía local; reforma constitucional; gobiernos locales.

\begin{abstract}
Review of tho book from Manuel ZAFRA VICTOR, La autonomía local en una Constitución reformada. Centro de Estudios Políticos y Constitucionales. Madrid, 2020.

Local autonomy has been turned into a matter subject to distribution of powers between the State and the Autonomous Communities, departing for this reason from its original conception. To the extent that the Autonomous Communities have tried to internalize it, it has been the state legislator who has come out in their defense. The solution to this situation is based on the proposal of detailed regulation in a possible constitutional reform, which delimits a nucleus of clear functions on specific matters that allow a real development of the political autonomy of local governments.
\end{abstract}

\section{KEYWORDS}

Local autonomy; constitutional reform; local government.

No es fácil efectuar la recensión de una obra del Profesor Zafra Víctor. La profundidad de su pensamiento, la capacidad de análisis y la agudeza de su visión holística en una materia tan compleja como incomprendida dificulta hacer justicia a su pensamiento. 
El libro que me planteo recensionar tiene un perfil politológico, que no jurídico y consta de dos partes más un epílogo que lo redondea. La idea principal que analiza es que la autonomía local es una parte inacabada de la Constitución, de forma que la misma no alcanza, ni en su definición, ni en su interpretación a conformar a las entidades locales como un nivel territorial de gobierno con capacidad para definir sus propias políticas bajo el paraguas de la Ley. Además, el TC ha permitido la existencia de una autonomía local acordeónica que la desdibuja al primar al legislador estatal, que dispone de una amplia capacidad para imponer las bases, y al autorizar al legislador sectorial a disminuir o aumentar el principio de autonomía local para potenciar su propia capacidad política como legislador sectorial al utilizarla como un asunto sujeto a reparto competencial. Gozan de preferencia los legisladores estatal y autonómico en detrimento de la virtualidad política de los dos miembros de la comunidad política local, municipios y provincias que acuden solitarios a gestionar en lo que los otros dos niveles de gobierno territorial le permiten.

La primera de las partes la identifica con dos ideas que laten con fuerza: la ausencia de un legislador de autonomía local y la concepción de una autonomía sometida a reparto competencial. Ambas conforman la necesidad de modificar el statu quo otorgado por la interpretación del TC hizo de la autonomía local desde la importante Sentencia 214/1989.

Este estado de cosas es evidenciado con fuerza desde el primer momento en tanto que el título constitucional utilizado por el Estado para legislar ha sido el artículo 149.1.18, frente a la asunción estatutaria autonómica al amparo del apartado 3 del mismo artículo, lo cual ha sido una fuente inagotable de problemas residenciados en el TC, cuya jurisprudencia no se ha mantenido uniforme. "La discutible conclusión de la fundamentación constitucional era evidente: las bases estatales salvaguardaban la autonomía local frente a la legislación autonómica de desarrollo» (pág 60). Una muestra de la capacidad del Tribunal para apoyar la defensa de las bases estatales como muro frente a una voracidad competencial inabarcable de la legislación autonómica la encontramos en las diferentes posiciones mantenidas en torno a la pertenencia o no al bloque de constitucionalidad de la Ley 7/58. Empezando por la STC 214/1989 con base en la 32/1981, el Tribunal enraíza la ley en la interpretación conjunta de los artículos 137, 140 y 141. En la 11/1999, sin embargo, el esquema pasa por arbitrar la autonomía local con base en la conjunción de los artículos 137 y 149.1 .18 en relación directa a los artículos 65 y 66 de la Ley $7 / 85$, con lo que pasa a identificar dos factores: la autonomía constitucionalmente garantizada y la competencia estatal, lo que lleva a una modificación de la norma de contraste. Ya no estamos ante el bloque de constitucionalidad sino ante la ampliación del poder territorial del Estado lo que viene a garantizar de nuevo que sea el Estado el que articule la modulación de un poder político en cierto modo ajeno y al que debe respeto institucional.

El autor entra a explicar el debate doctrinal respecto de la garantía constitucional de la autonomía local. La autonomía local se concibe como un principio y como un derecho de configuración legal y eso la sitúa en una posición de vulnerabilidad e inseguridad jurídica. De ahí la deferencia del TC hacia el legislador, puesto que la zona de certeza se llena con el mínimo del derecho de participación mientras que en el halo de la zona de penumbra se mueve la graduación de este principio. "La manera de sortear la dificultad es el principio in dubio pro legislatore y declara la inconstitucionalidad cuando el legislador sectorial o de régimen local ignore la autonomía.» (pág 87).

Examinada la cuestión doctrinal, el autor avanza en la aseveración inicial: la autonomía es un principio que oscila entre el mínimo (zona de certeza) hasta lo que el legislador (sectorial o general) quieran, pero siempre sin que el máximo pueda consolidarse (zona de penumbra). Sin embargo, dado que la Constitución no jerarquiza el valor «autonomía local» frente a otros valores, es necesario ponderar los principios en juego de forma que la mayor intensidad de uno u otro deberá verse a la luz de la coexistencia de estos valores sin que haya que sacrificar uno u otro sino conservándolos, por ejemplo cuando ha determinado que el valor de la autonomía debe ser interpretado en clave o en ponderación con los principios derivados del artículo 135 de la Constitución, como ha sucedido en las Sentencias respecto de la impugnación de la LRSAL de 2013.

Desprovistos los entes locales de la garantía constitucional que otorgase un verdadero derecho de intervención y de una legislación integrada dentro del bloque de constitucionalidad, el autor demuestra claramente que la postura del TC es proclive a otorgar el beneficio de la constitucionalidad de las bases estatales conforme al principio in dubio pro legislatore. Para el Tribunal sólo la zona de certeza queda constitucionalmente garantizada. Allí donde sea posible una interpretación de la norma eventualmente inconstitucional que pueda ofrecer el mínimo de garantía institucional, optará por declarar la constitucionalidad en base a esta opción. El autor acude a la interpretación de K. Hesse y Habermas en la forma de entender la zona de certeza y de penumbra de la interpretación jurisprudencial, lo que acredita que sólo cuando el Tribunal se enfrenta a una eliminación radical del mínimo margen de intervención local es cuando declara su inconstitucionalidad. Así 
permite al legislador sectorial convertir la autonomía en la simple emisión de un informe. La deferencia del Tribunal hacia el legislador supone en este caso que la autonomía local carece de rango cuando se trata de fijar competencias puesto que para tal fin debe llamarse a las bases y a la normativa sectorial sin que ambas contengan un marco preciso (zona de penumbra) en la que el juzgador siempre favorecerá la opción política. No se trata ciertamente de que la ley sea desarrollo de la Constitución, sino que ésta permita la necesaria opción política estatal en el desarrollo de la concepción que se tenga de la autonomía local.

Las posibles dudas en torno a la consideración casi residual del principio de autonomía local se despejan tras la entrada en vigor de la LRSAL. El autor hace una llamada a la ausencia de vocación política del principio de autonomía local al ser puesto en contraste con el coste estándar, posterior coste efectivo y la compleja referencia a la necesidad de justificación de una opción política que no afecta a otros elementos del Estado. «Aunque el alto órgano consultivo no lo expresa en estos términos, sus reservas parecen indicar que el coste en la prestación de un servicio es una decisión política..., que el alumbrado público responda a criterios ecológicos, es una genuina medida política que se adopta con independencia de parámetros económicos» (pág 168). Las Diputaciones son ahora los prestadores de servicios a la ciudadanía cuando los verdaderos destinatarios de las competencias provinciales, como explica el autor, son los municipios. El TC, una vez más, ha aplicado el precedente y ha obviado la realidad política local, vertebrando una serie de Sentencias que no han alcanzado a ver la verdadera dimensión política del poder local. La zona de certeza ha triunfado y la zona de penumbra permanece sin más luz que la que el legislador sectorial o estatal quiera darle.

Por su parte las Diputaciones son ubicadas en su necesario ajuste como institución intermunicipal. «La opción que propone este trabajo es la de constitucionalizar una instancia intermunicipal. Se trata de una solución intermedia entre la plena interiorización autonómica y el vigente reparto bifronte» (pág 54). La Provincia y su institución de gobierno cobra sentido entonces como institución intermunicipal dotada de autonomía de carácter instrumental, con competencias funcionales y legitimación indirecta.

La segunda parte del libro desarrolla con mayor detalle las propuestas en orden a la reforma constitucional y completa el marco teórico con la propuesta de reforma constitucional propiamente dicha.

Las ideas se expresan en las páginas 197 y 198 y vienen presididas por «mayor densidad regulatoria en una Constitución de detalle y remisión a un legislador cualificado de autonomía local» (pág 197).

Una cuestión básica que enfatiza la idea de reforma constitucional es la previsión en ley de mayoría cualificada de la necesaria financiación incondicionada. Ambos factores deben ir conectados y en lógica coherencia. De ahí que sea necesario que la Ley de mayoría reforzada recoja la financiación incondicionada como elemento de posibilismo político local.

La clave interpretativa es el artículo 6 de la CEAL. El diseño del gobierno local requiere adaptación de estructuras y medios a la verdadera naturaleza de esta realidad y ello conlleva alteración del sistema de fuentes con clara primacía de la autoorganización local en detrimento del espacio a la ley autonómica. El problema es que, en la interpretación Constitucional, la capacidad del Estado para determinar la organización institucional es la zona de certeza de esta relación, zona que debe dejar un margen para ser ocupado, primero por las comunidades autónomas y luego por las entidades locales. Eso ha permitido la intromisión en el esquema institucional hasta límites aparentemente exagerados, como el caso de los Municipios de gran población, cuya regulación deja pocas posibilidades a los gobiernos locales para dotarse de una organización específica que les ayude en la eficacia de gestión. «Las bases estatales no limitan a la preceptiva creación del órgano, sino que lo extiende a la composición, funciones y funcionamiento, una intensidad justificada por afectar a un órgano que garantiza un tratamiento común a los administrados» (pág 209).

Dentro de la opción defendida por el autor, destaca su opinión sobre la no adscripción, asumiendo la necesidad de reivindicar el valor y la esencia de la democracia mediante la regulación mayoría-minoría, aumento de la rendición de cuentas (responsabilidad interelectoral), modificación del proceso de elaboración de normas locales y estatuto de representantes políticos.

La intermunicipalidad no tiene que estar vinculada a la necesaria existencia de la Provincia como elemento de división territorial pero sí mantener la legitimidad indirecta que actualmente tiene. «La propuesta de regulación constitucional en caso de reformar sería la de desvincular la provincia como división territorial y la necesidad de creación de una instancia intermunicipal de creación autonómica» (pág 221). Regulada de esta manera, se acaba con la disfunción existente alrededor de la Provincia cobrando vida una división territorial constitucional en torno a la Comunidad Autónoma, unido a la potenciación de la prestación de servicios a municipios en condiciones de legitimidad política y libertad de decisión a través de la instancia intermunicipal, ya que lo importante no es el nombre, sino sus funciones. 
La articulación pasa porque la iniciativa corresponda a la Diputación, lo que supone dirección política, pero proyectada sobre las prioridades municipales. La ponderación de estos intereses locales corresponde mediante mesas de concertación a la Diputación, pero con el necesario auxilio y colaboración leal de los municipios que podrán acabar o no en acuerdo correspondiendo la decisión final en caso de discrepancia a la Provincia.

Finalmente, la reforma, al ser la autonomía local un poder territorial más, debe permitir su participación en las instituciones de Comunidades Autónomas y Estado, articulando un entramado de relaciones de igual a igual, cada uno en el ámbito de sus competencias. Como niveles de gobierno, su interacción «transcurre por cauces procedimentales de negociación y deliberación que garanticen una cierta paridad institucional para que la posición de ventaja del mayor presupuesto no provoque asimetría y subordinación» (pág 254). Eso unido a la concertación, son la clave para entender la intermunicipalidad, consiguiendo que esta propuesta de reforma constitucional, vaya mucho más allá que algunas operaciones estéticas que se pudieran producir en un futuro.

Acabo ya reconociendo el valor añadido que el prólogo del Profesor Jiménez Asensio le aporta. Sus conclusiones son la prueba de que este libro pertenece ya a la lista de libros imprescindibles para conocer y mejorar la democracia local y los gobiernos locales.. 